\title{
Identidades, aprendizagem e mediação intercultural: uma análise antropológica
}

Ricardo Vieira Ana Vieira

Escola Superior de Educação e Ciências Sociais Instituto Politécnico de Leria - Portugal

\section{Resumo}

Neste texto é discutida a problemática das identidades plurais e sua reconstrução em contextos de educação escolar e não escolar. Discute-se a construção e incorporação de atitudes monoculturais, multiculturais e interculturais, por parte do self, e reconceitualiza-se o conceito de mestiçagem como capaz de dar conta da complexidade identitária dos sujeitos da contemporaneidade em que a mediação intercultural e sociopedagógica, numa lógica preventiva, reabilitadora e antropológica, surge como instrumento fundamental à hospitalidade das culturas e dos sujeitos que a habitam e (re)constroem. Mediante os processos de ensino-aprendizagem, todos nós acabamos por atravessar uma multiplicidade de culturas, códigos linguísticos, mais restritos, mais elaborados, mais locais, mais universais, crenças, valores, saberes, etc. $\mathrm{E}$ somos, cada vez mais, mais mestiços, culturalmente. No tipo de reconstrução identitária do self, nos trânsitos culturais potenciados pelas aprendizagens, tornando-se cada vez mais nesse mestiço, parece ter um papel relevante o mediador intercultural, como tentaremos mostrar ao longo deste ensaio.

Palavras-chave: Identidades. Aprendizagem. Mestiçagem. Mediação. Interculturalidade. 


\section{Identities, learning and intercultural mediation: an anthropological analysis}

In this text it is discussed the problem of plural identities and its reconstruction in contexts of school education and non school education. It is discussed the construction and incorporation of multicultural, intercultural and monocultural attitudes on the part of the self and it reconceptualizes the concept of cultural métissage as capable to handle the complexity of the identity of the subjects of contemporary times where intercultural and sociopedagogical mediation appear as fundamental instruments to the hospitality of the cultures and of the subjects who inhabit them and (re) construct. Through the processes of teaching and learning, we all end up by having a multiplicity of cultures, language codes, more restricted, more elaborate, more locals, more universal, beliefs, values, knowledge, etc. being increasingly culturally more mestizos. In the type of reconstruction of the personal identity, the intercultural mediator has a relevant role, as we will try to show throughout this trial.

Keywords: Identities. Learnings. Métissage. Mediation. Interculturality.

\section{Identidades, aprendizaje y la mediación intercultural: un análisis antropológico}

En este texto es discutido el problema de las identidades plurales y su reconstrucción en contextos de escolarización y educación no escolar. Aborda la construcción y la incorporación de las actitudes monoculturales, multiculturales e interculturales, por parte de uno mismo y reconceptualiza el concepto de mestizaje como capable de manejar la complejidad de la identidad de los sujetos de la época contemporánea donde la mediación intercultural y sociopedagógica aparecen como instrumentos fundamentales para la hospitalidad de las culturas y de los sujetos que las habitan y (re) construyen. Através de los procesos de enseñanza y aprendizaje, todos terminamos por tener una multiplicidad de culturas, códigos de idioma, más restringidos, más elaborados, más lugares, más universales, creencias, valores, conocimientos, etc. siendo cada vez más mestizos, culturalmente. El tipo de reconstrucción de la identidad de uno mismo, en los trânsitos culturales incitados por las aprendizagens, se tornando cada vez más mestizo, parece tener un papel relevante el mediador intercultural, como intentaremos mostrar a lo largo de este ensayo.

Palabras-clave: Identidades. Aprendizajes. Mestizaje. Mediación. Interculturalidad. 


\section{Aprendizagens e reconstrução identitária: a gestão do self compósito}

Toda a aprendizagem produz (trans)formações. Transformações em termos cognitivos, como é o caso da aprendizagem do cálculo matemático, económico e de todas as literacias, mas não só. Há uma transformação do eu sempre que se aprendem novos conhecimentos, seja na escola, seja nos diversos contextos culturais. E essa aprendizagem/formação, se efetivamente houver apreensão, que implica autoconstrução (Vieira, 2014), origina transformações cognitivas (Vieira, 2011). Por isso a formação é transformação (Nóvoa; Finger, 1988; Pineau, 1983; Vieira, 2011). Mas as aprendizagens operam, também, transformações culturais e identitárias (Vieira, 2009; 2014). Ninguém aprende no vazio cultural, pelo que as aprendizagens cognitivas são acompanhadas de identificações e desidentificações com os textos e contextos de aprendizagem e de aquisições e rejeições culturais. Da triangulação complexa entre a autoformação, a heteroformação e a ecoformação (Pineau, 1983) pode, assim, resultar a emergência de novas formas culturais, terceiras culturas (Brockman, 1998) e, nas pessoas, em concreto, submetidas a novas formações e aprendizagens, terceiros instruídos (Serres, 1993). 0 sujeito (trans)formado renasce de novo. Já não é apenas produto de uma socialização primária num dado contexto. É agora um terceiro instruído; uma terceira, quarta, quinta e mais dimensões de ser e estar; uma (re)construção identitária, uma recriação entre o background já possuído e as alternativas culturais constatadas e interiorizadas pelo indivíduo. Vale a pena recordar as próprias palavras de Michel Serres:

Singular e única, produto dos genes do pai e da mãe, a criança só evolui através de cruzamentos e fusões. Toda a pedagogia retoma o processo de gestação e nascimento do indivíduo. Nado canhoto, aprende a servir-se da mão direita; permanecendo esquerdino, renasce destro pela convergência das duas direcções e hemisférios. Nascido gascão, torna-se francês através da educação, ou seja: mestiço. E sendo gascão em francês pode tornar-se em espanhol, italiano, inglês ou alemão, se aprende uma nova língua e cultura, guardando porém a de origem. (Serres, 1993, p. 19)

Esse terceiro instruído, esse sujeito mestiço, culturalmente falando, corresponde ao processo de reconstrução identitária. A construção/ reconstrução da identidade corresponde sempre à integração do novo no já possuído (tal como em determinada aprendizagem), donde resulta não uma adição, mas antes uma integração feita um pouco ao modo de cada um. Por isso autoconstruída na triangulação com a eco e a heteroformação. Por isso idiossincrática. 
Recriam-se novas culturas, que se tornam mais mestiças ${ }^{1}$. Nos contextos anglo-saxónicos, é o conceito de híbrido que é provavelmente mais usado para indiciar a mistura cultural que, contudo, nunca é homogénea, como aqui exploraremos. Efetivamente, raros são os textos em inglês que usam o conceito de "métissage" ou de mestizo. Encontramos Anzaldúa (1987), que nos fala de new mestiza e de Homi (1996), que se refere a este conceito em "culture's in between"; Vieira (2014), que analisa "life stories and métissage", para compreender a mestiçagem das identidades pessoais, mas não muito mais. É muito mais usual encontrar-se o conceito de híbrido. Mas o conceito de híbrido remete para uma classificação muito cartesiana em que a normalidade cultural se situa num dos polos, em que tudo o que não é nem um nem outro surge como impuro, híbrido. Mas não há meios termos na linguagem da complexidade: há terceiros (Serres, 1993), mestiços, dimensões novas construídas a partir de misturas que mantêm traços de origem, traços de adoção e traços de criação.

Logo, o conceito de mestiçagem, devidamente percebido no contexto das novas análises mais francófonas, remete sim para o intercultural, mas nunca para o multiculturalismo, que simplesmente tolera as diferenças culturais coexistentes num espaço, mas sem promover o diálogo da convivência que leva à mestiçagem e à assunção de um novo paradigma, que rompe com a ideia de pureza, para mostrar que todas as culturas são dinâmicas, compósitas e mestiças.

O híbrido acaba por ser uma classificação usada por quem tem um olhar monolítico. Creio que Stuart Hall tem este cuidado quando se analisa a si próprio como um híbrido. Ele tem bem consciência da fragilidade do conceito de hibridez (Hall, 1992), que, como é sabido, provém da biologia, tal como o de mestiço, mas, ao contrário deste, que permite a criatividade (Laplantine; Nouss, 1997; Wieviorka, 2002; Serres, 1993), o híbrido não se reproduz biologicamente. 0 híbrido está condenado à extinção. Por outro lado, também o sincretismo leva à ideia de fusão, de melting pot, o que não corresponde ao paradigma de criatividade pelo encontro cultural nas pessoas, na música, na pintura, na cultura em geral, em que o todo e as partes coexistem dinamicamente nessa nova totalidade mestiça. (Laplantine; Nouss, 1997; André, 2005; Vieira, 2014)

Quanto ao multiculturalismo lo political correcteness norte-americano, a reivindicação do direito das minorias e das «comunidades étnicas», a apologia do pluralismo terapêutico...), ele é, do nosso ponto de vista, exatamente o 
contrário da mestiçagem. Funda-se na coabitação e na coexistência de grupos separados e justapostos, firmemente virados para um passado que convém proteger do encontro com os outros. (Laplantine; Nouss, 1997, p. 75)

Claro que, também, o conceito de mestiçagem não pode ser usado ingenuamente:

É certo que, de entre estas noções, o conceito de mestiçagem é o que mais armadilhado se apresenta, quer pela sua génese histórica no contexto de processos de colonização forçada sob o peso, a força e o poder da cruz, das correntes, do chicote, da pólvora e da violação, quer pela possibilidade da sua contaminação, pelo confronto com a noção de pureza a que aparece como contraponto, contaminando maniqueisticamente com um sentido de impuro aquilo a que se refere [...] (André, 2012, p. 95-96)

Contudo, se usado contextualizadamente e com a prudência necessária, e despindo-o das conotações racialistas, assimilacionistas e monistas que não lhe são intrínsecas, não nos parece ser menos adequado, bem pelo contrário, do que outros conceitos que surgem como alternativa, como é o caso de hibridismo. Como refere, ainda, João André, filósofo de formação mas que tem um trabalho notável, em Portugal, de aproximação à antropologia, à educação intercultural e ao pensamento mestiço,

o conceito de hibridação ou hibridismo tem vindo a ser utilizado por outros autores que olham com reservas para o conceito de «mestiçagem». É o caso, nomeadamente, de Garcia Canclini que, na sua obra Culturas Híbridas: Estratégias para entrar y salir de la Modernidade, México, Girijalbo, 1990, prefere esta expressão para caracterizar os processos de misturas interculturais que se verificam atualmente, mas que, simultaneamente, se caracterizam também pela incorporação dos efeitos de histórias e memórias diversificadas. (André, 2012, p. 96)

Esta lógica do pensamento mestiço, que se opõe ao pensamento monista dominante, deixa-nos, por vezes, apreensivos. Efetivamente, somos muito o produto do cartesianismo e do positivismo que nos ensinou durante séculos a pensar factualmente e não processualmente; a pensar em estruturas e não tanto em processos. E, quando se fala em mestiçagem, não se trata simplesmente de juntar, misturar, cruzar, etc. Contudo, ao nível do senso comum, na medida em que mestiço se contrapõe, habitualmente, a puro, privilegia-se, ainda que inconscientemente, o puro como bom e o mestiço como o contaminado. A mestiçagem deverá ser considerada como algo diferente de justaposição ou de fusão: "remete para a tensão constitutiva da relação 
de diferentes, para o dinamismo que ela implica [...] E para a conflitualidade criadora". (André, 2005, p. 126)

João Maria André sintetiza as mestiçagens em dois grandes grupos: "Se há mestiçagens que se constituem com base no encontro e no diálogo, outras há que resultam da conquista, da violação, do sangue e do sémen misturados num projecto de domínio que é simultaneamente, não poucas vezes, um projecto de exterminação das diferenças e de homogeneização da alteridade". (André, 2005, p. 104)

Quando aplicamos o conceito de mestiçagem à identidade pessoal e à cultura pessoal, como foi reiterado atrás, é, justamente, para dar essa ideia não só do mix, mas, também, como pensamos que já ficou claro, do processo, do inacabado que é cada sujeito em cada momento da sua história de vida. Não nos podemos pensar como seres estáticos. Há sempre algo que se altera em nós a partir das relações que estabelecemos com o outro. Existem sempre trocas entre ambos. E é dessas trocas com um outro que vamos construindo as nossas próprias aprendizagens (Vieira, 1999 a; 2011). Assim, construímos o nosso caminho ao caminhar - através das múltiplas experiências em que vamos participando ao longo da nossa existência - e vai-se (re)construindo a nossa identidade na medida em que as nossas identificações culturais não são exclusivas nem sempre as mesmas, como é o caso particular do trânsfuga Intercultural (Bourdieu, 2005; Vieira, 1999 a e b; 2009). Portanto,

[...] nem todos somos feitos de uma só peça, e como observa Amy Gutman, nem toda a gente é tão multicultural como Rushdie, mas as identidades da maior parte das pessoas, e não só das elites ou dos intelectuais ocidentais, são formadas por mais do que uma cultura singular. São também as pessoas, e não apenas as sociedades, que são multiculturais. (Wieviorka, 2002, p. 23)

Na educação, seja escolar ou não escolar, a mediação intercultural e sociopedagógica (Vieira, 2012) surge como uma ferramenta fundamental para gerir tensões sociais e encontros e desencontros culturais para que as mestiçagens possam ser o mais multitópicas possível (Vieira, 2013 a), como veremos adiante.

Compreende-se que quem vive a estabilidade cultural, com poucas interações com a alteridade, tem tendência a ter atitudes mais monoculturais e mais próximas do comportamento modal da cultura em que se inserem originalmente com os seus pares e seus familiares (Vieira, 2009). As que, por diversas razões, sofrem processos de mobilidade social, quer ascendente quer descendente, ou atravessam vários contextos socioculturais na trajetória 
social em função de processos migratórios, de processos de escolarização ou outros, são submetidas a processos de metamorfose cultural e reconstroem, assim, as suas identidades pessoais: reconstrói-se a imagem que o eu tem de si e a que oferece aos outros. (Dubar, 2006)

No caso do imigrante, um bom exemplo para pensar a "terceira cultura" e a reconstrução identitária, este procura construir o seu novo eu, situado entre a cultura de origem e a cultura de chegada, separando esses dois mundos, conciliando-os ou construindo uma terceira dimensão identitária, procurando a via mais segura do ponto de vista ontológico (Camilleri, 1993). Falamos, portanto, da complexa questão das estratégias que os sujeitos adotam para gerir os múltiplos contextos culturais de uma forma que entendem menos invasiva na edificação permanente da sua identidade pessoal e social, de modo a evitar a crise identitária à qual estão particularmente sujeitos na situação de processo migratório.

A gestão das identidades apresenta-se como um terreno dilemático e conflituoso, de negociação incessante entre as condições objetivas e subjetivas. Nas escolas, por exemplo, é fundamental que os professores percebam quão doloroso podem ser, para alguns, os processos de transformação que a cultura hegemónica designa, habitualmente, de integração. Daí, como tem frisado Ana Vieira (Vieira, 2012; 2013 a e b), a importância de pensarmos em mediadores interculturais e sociopedagógicos para trabalharem a par dos professores - como veremos no final deste ensaio -, para mediarem preventivamente e resolutivamente tensões sociais e aculturações que façam sentido para o eu plural dos sujeitos em questão.

0 conceito de estratégia identitária indica que o indivíduo possui margem de manobra para se inventar diferente (Camilleri et al., 1990). É mediante estas estratégias que a identidade se constrói ao longo da vida, ainda que nem sempre estas sejam utilizadas de forma consciente. As reconfigurações identitárias vão depender, assim, dos lugares estruturais e das possibilidades de agência que neles vão encontrar (Magalhães, 2001; Dubar, 2006) bem como dos adultos mediadores e inspiradores de determinadas referências culturais e educacionais. (Vieira, 2013a)

Quem experimenta contextos culturais muito diversos ou vive processos migratórios mediante múltiplas referências culturais e situações complexas tende para o hibridismo identitário, de acordo com Hall (2003a, 2003b), ou para a mestiçagem (Laplantine; Nouss, 2002; Vieira, 2009, 2011, 2014; André, 2012). Conforme destaca Stuart Hall, “[...] na situação de diáspora, as identidades se tornam múltiplas” (Hall, 2003 a, p. 27). Neste sentido, a busca dos sentidos e pertenças identitárias torna-se complexa, requerendo a ajuda de mediadores 
interculturais (Vieira, 2013b) e dos sujeitos um trabalho de reflexividade e (re)construção constante de si, apelando a mecanismos próprios que thes permitam gerir as suas subjetividades e idiossincrasias com “um pé em cada local". (Sarup, 1996, p. 7)

Para muitos imigrantes, o sucesso na sociedade de acolhimento leva ao quebrar com algumas fronteiras estreitas do lugar de partida e à integração numa nova cultura que convida a metamorfoses ou leva, mesmo, às vezes, a uma espécie de transfusão cultural (Vieira, 1999a, 1999b, 2009) nos seus modos de ser e nos seus projetos de vida.

Um estudo recente realizado em Portugal com imigrantes brasileiros, (Vieira e Trindade, 2008; Vieira, Margarido e Marques, 2013) procura mostrar, utilizando a teoria da transfusão cultural (Vieira, 1999 a e b; Vieira, 2009) e a observação da heterogeneidade de modos de viver entre culturas, o jogo das fronteiras simbólicas de imigrantes que se assumem ora como brasileiros em Portugal; como luso-brasileiros; ora como cidadãos do mundo, idealizando a utopia de uma "imigrónia", em que os imigrantes, os considerados "sem terra”, são reconhecidos como tendo identidades compósitas e mestiças, capazes de se adaptar a vários territórios identitários para além dos da cultura de origem. Gilberto Velho refere que a “[...] existência de projectos individuais está vinculada a como, em contextos sócioculturais específicos, se lida com a ambiguidade fragmentação-individualização" (Velho, 1987, p. 26). Estamos perante a possibilidade de ilustrar, por um lado, a ideia de identidade objetiva - a do bilhete de identidade, da naturalidade, da nacionalidade; e, por outro, uma identidade muito mais interior, muito mais subjetiva, que é esse processo de identificação na convivência com o outro, com a alteridade, já que o imigrante encontra-se frequentemente perante sensações de ambivalência ou de contradição entre os valores que o incorporam e outros que se the surgem ao mesmo tempo que emerge a possibilidade de fazê-los seus. Surge assim "[...] uma incerteza de não se saber a que lugar é que se pertence, a incerteza de não se saber exatamente de que terra é que se é". (Vieira, 2009, p. 54)

Para explicar as diferentes estratégias usadas por estes imigrantes brasileiros em Portugal, nesse estudo em que está disponível, também, um videograma com todas as entrevistas realizadas (Vieira; Margarido; Marques, 2013), procurámos compreender, por meio de vários modelos paradigmáticos, as diferentes formas que os imigrantes encontram para lidar com a situação de aculturação: 1) rejeitando a cultura de origem (o caso do oblato); 2) rejeitando a cultura de chegada num dado momento lo caso do monocultural de acordo com a cultura de partida); 3) vivendo de forma ambivalente entre as duas (o 
caso do multicultural); e 4) inventando a terceira margem, que corresponde a uma atitude pragmática de integração na sociedade de destino, incluindo as diferenças culturais experimentadas ao longo da história de vida num self intercultural (o caso do trânsfuga interculturall. Situamo-nos, assim, perante quatro modelos polarizados que podem revelar-se úteis ao norteamento da estratégia de gestão identitária.

Refletindo, em primeiro lugar, sobre o caso do oblato. É pertinente salientar que alcançar o sucesso numa nova sociedade poderá significar ceder à maneira de pensar da nova cultura e, não raras vezes, resultar no abandono da cultura de origem em favor de uma segunda cultura. Aceder a uma nova cultura, muitas vezes diferente da cultura de nascimento, poderá, também, significar deixar para trás a primeira identidade e criar uma outra: aplicar um corte com uma antiga forma de pensar e viver; tornar-se alguém que já não é o que foi; transformar-se em alguém que vive inteiramente de acordo com a cultura de chegada. Trata-se do oblato. Este modelo aplica-se àqueles que têm medo de falar de si e fazer descobrir o seu passado. Nunca falam das suas origens, dos lugares onde nasceram, cresceram e viveram antes de imigrar. Procuram transmitir a ideia de que são produto da cultura de chegada. $\mathrm{Na}$ sua comunicação, nunca usam elementos dos contextos da infância nem da cultura de partida, e esta posição permanece mesmo quando se encontram com pessoas da mesma origem. 0 oblato educa os seus filhos para a cultura de chegada - a segunda margem - e nega-lhes o passado. Frequentemente, ao atingir alguma maturidade social, muitos filhos de imigrantes lamentamse em relação à ausência do conhecimento de um passado, levando-os em busca das suas raízes nos países de origem dos seus antepassados. Nos trabalhos realizados junto de diferentes comunidades imigrantes quer na América do Norte (Cunha, 1997), quer na Europa (Gusmão, 2004), é constante a idealização da terra dos antepassados por parte da segunda geração.

Relativamente ao caso do monocultural, de acordo com a cultura de partida, este retrata os imigrantes que, vivendo entre culturas, revelam uma atitude que privilegia uma dimensão ontológica e os leva a viver de acordo com a cultura de origem. Trata-se daquele que parte em relação à cultura original, mas pensa o mundo sempre centrado nos valores desse primordialismo identitário: a primeira margem. 0 apelo das raízes influencia o comportamento do sujeito de tal forma que pode levar à recusa da cultura de chegada.

Em relação ao modelo do bilingue ou bicultural, ou multicultural, tomemos como exemplo o sujeito que habita duas ou mais margens e que consegue ser ator e sujeito completamente contextualizado nos dois ou mais mundos culturais. Alguns autores referem, efetivamente, a existência de diferentes 
eus, afirmando que, num indivíduo, coexistem várias identidades, cujas manifestações ocorrem conforme e de acordo com a especificidade dos contextos (Laplantine e Nouss, 2002; Maalouf, 2002). Para muitos imigrantes vindos de sociedades pré-modernas ou pré-burocráticas, viver entre estes dois mundos pode levar a uma divisão deles próprios, causando aquilo a que Roger Bastide (1955) chamou de princípio de corte. Com este modelo, descrevendo a situação dos afro-americanos no Brasil, o referido autor tem em mente a capacidade que os indivíduos manifestam de viver em cada mundo como uma pessoa diferente, fazendo uso de diferentes racionalidades. Este é o caso, por exemplo, da pessoa que trabalha num banco e que, algumas horas mais tarde, pode estar a tomar parte no candomblé.

0 caso do trânsfuga intercultural encontra-se traduzido nos sujeitos que utilizam a cultura de origem como um leque de experiências tão válidas como as muitas outras presentes quotidianamente na sociedade de acolhimento, levando à conceção de um eu intercultural. Neste modelo, há uma aceitação da nova cultura sem rejeitar a antiga. Consiste num tipo de estratégia identitária que é a de viver perfeitamente entre os dois mundos, criando uma terceira cultura no processo do trânsito intercultural. 0 trânsfuga intercultural integra a cultura do país de chegada no seu universo pessoal, oferecendo uma nova dimensão à cultura de origem sem a destruir ou substituir, facultando-the uma terceira dimensão resultante da integração comparativa do eu e do outro, do nós e do eles. Um trânsfuga intercultural identificar-se-á com a alegação de Amin Maalouf (2002): “Não tenho várias identidades, tenho apenas uma, feita de todos os elementos que a moldaram segundo uma dosagem particular que nunca é a mesma de pessoa para pessoa" (Maalouf, 2002, p. 10). 0 sujeito com estas características tem a capacidade de inventar a terceira margem, como refere Guimarães Rosa (1988), o que corresponde a uma atitude e a uma identidade local que inclui as diferenças culturais por que se passou ao longo da história de vida, num self intercultural. Os imigrantes de tipo trânsfuga intercultural assumem a sua mestiçagem (Vieira, 2009, 2011; André, 2012) e não têm qualquer problema em viajar intelectualmente aos contextos do passado de que tiram proveito para o presente e futuro.

Os casos apresentados constituem modelos orientadores das múltiplas formas de gerir as pertenças identitárias. São possibilidades perante a diversidade de estratégias sociais de sobrevivência (Camilleri, 1989) utilizadas pelos sujeitos nessa gestão da diversidade cultural. Para além destas possibilidades, existem tantas outras variantes quanto terceiros (Serres, 1993) - e todos os indivíduos são terceiras pessoas (Vieira, 2009). Por vezes, os sujeitos afastam a consciência dessa condição, assumindo-se como puros, 
como monoculturais; como se tal pureza existisse do ponto de vista cultural e a identidade não fosse mestiça. (Vieira, 2009; 2011; 2014)

Esta realidade existe, claro, para além dos brasileiros residentes em Portugal, em particular, e dos imigrantes, no geral. As trajetórias sociais e as condições objetivas vividas pelos sujeitos podem criar identificações interiores muito diferenciadas. Não existem, hoje, culturas puras. Somos, cada vez mais, culturalmente mestiços; $A$ educação escolar e não escolar potenciam encontros e desencontros, diálogos, aprendizagens, (trans) formações recriando novas mestiçagens - essa terceira dimensão de que temos vindo a falar e que, por vezes, leva a que o indivíduo não consiga gerir a complexidade da sua mestiçagem e experiencie, tantas vezes, essencialmente perante a ausência de mediações interculturais (Vieira, 2013 a e b), crises de identidade. (Dubar, 2006)

\section{Da Interculturalidade e (re)descoberta de si e do papel da mediação intercultural}

Essencialmente, em França, a reflexão sobre a mestiçagem e o intercultural tem estado muito ligada aos problemas das migrações às questões do ensino para imigrantes, problemática dos trabalhadores estrangeiros, etc. (Camilleri, 1989). Mas o intercultural não se reduz às relações internacionais e interétnicas (Gusmão, 2004). Em pesquisas no âmbito da antropologia da educação, e da mediação intercultural e sociopedagógica, temos procurado frisar outras dimensões da reflexão sobre o intercultural e a mestiçagem. No contacto intercultural, o que se comunica não são verdadeiramente as identidades grupais, as culturais nacionais ou locais, mas, antes, as pessoas portadoras duma identidade pessoal, dinâmica, e sempre em gerúndio (Vieira, 2009), ela própria multicultural. Até numa visita de estudo da turma a determinado contexto, meio, exposição, ambiente, por exemplo, há sempre diligências pessoais que se podem revestir de aquisições de saberes, descoberta de tradições, paisagens, etc. Mas também se põem em contacto diferentes modos de vida, maneiras de pensar e de sentir próprios de grupos e das pessoas elas mesmas, num processo de interculturalidade.

A heterogeneidade cultural dos grupos é interiorizada, incorporada, de modo idiossincrático, por parte de cada aluno nesses encontros. Cabe ao professor desempenhar o papel de mediador intercultural (Vieira, 2011; Vieira, 2012; Vieira, 2013 a e b) e ajudar o aluno a (re)construir o seu eu intercultural, sem ambiguidades, sem grandes conflitos interiores ou receio de receber da 
alteridade para si. Como nos deixou bem claro Saint-Exupery, " Sou um pouco de todos que conheci, um pouco dos lugares que fui, um pouco das saudades que deixei e sou muito das coisas que gostei [...]". Mas, por vezes, num mundo que continua a pensar, a ver e a avaliar a preto e branco, de acordo com lógicas binárias e monistas (Vieira, 2009), não é fácil que cada um de nós assuma a multiculturalidade em si, a mestiçagem de si (Vieira, 2011). Aí, o papel do professor, também ele como investigador e etnógrafo da sua própria escola e turma, como antropólogo dos seus alunos, como contributo para a construção também de crianças interculturais, que, podendo ser diferentes, possam, no entanto, comunicar-se. Daí que o professor deva interiorizar a mensagem da antropologia da educação, até ao ponto de sentir-se, ele mesmo, um antropólogo. Mas isso exige uma preparação antropológica dos professores, na formação inicial e na formação contínua. Não basta, não é suficiente uma relação professor-aluno empática. É preciso tirar partido da diversidade de contextos para construir práticas pedagógicas interculturais, pois "a pedagogia intercultural permite sair da alternativa binária e demasiado simplista: novos objetos, novas didáticas”. (Abdallah-Pretceille, 1990, p. 215 e 216)

É importante que cada profissional social, da educação ou não, tenha um conhecimento comparativo para além das circunstâncias imediatas do seu meio local. Há professores cuja trajetória social lhes deu esse treino de refletir as ações, de pensar o que se está a fazer, e porque se faz assim, e, no tocante aos outros, de procurar entender o seu entendimento. São pessoas que, no quotidiano, acabam por refletir frequentemente e pôr, assim, em prática a sua metacognição. Surge então, por continuidade, um conhecimento comparativo dos diferentes meios sociais por parte deste tipo de sujeitos que contribui para a relativização do conhecimento e culturals).

Por outro lado, também, há assim, uma melhoria qualitativa do seu próprio conhecimento e do entendimento das suas ações e saberes locais, pois o considerar das relações, entre um determinado contexto e o seu ambiente social mais amplo, ajuda a esclarecer o que se passa no próprio contexto. E comparar-se com o outro, que faz de modo diferente, implica, em primeiro lugar, conhecer-se a si próprio, tornar visível as suas práticas e representações sociais correlacionadas com a sua própria biografia que suporta tais atitudes e condutas. Depois, em segundo lugar, implica contactar com a alteridade e perceber as alternativas à eventual monoculturalidade do seu eu profissional. À partida, o docente, e não só, cai, não raras vezes, na tentação de considerar o que sucede habitualmente na sua vida quotidiana como o modo como efetivamente devem ser as coisas, as práticas e as ideias, para sempre e em 
todas os espaços. É o etnocentrismo comum a todos os mortais e a todas as culturas que urge ser relativizado. E, por isso, urge pensar, a este propósito, no papel da antropologia da educação na formação inicial, mas, também, na formação contínua, sempre, e não apenas para a adequação a uma reforma que se impõe normativamente. E importa pensar numa nova forma de fazer formação contínua, uma forma baseada essencialmente na reflexividade e na investigação: na investigação, por exemplo, das histórias de vida dos alunos que se tem, da própria autobiografia do docente e dos colegas, para se saber quem se é, quem se quer ser e como e quem são os outros. Enfim, uma formação contínua muito baseada, também, na reflexão autobiográfica.

\section{0 trabalho reflexivo com estudantes de mestrado da área da formação de professores e da área da mediação intercultural e intervenção social}

No pressuposto de que é preciso desenvolver a comparação e a reflexão sobre o quotidiano da sala de aulas, incidentes pedagógicos, tensões e conflitos que emergem nas aulas e na escola; que é preciso colocar várias mentes a pensar coletivamente sobre as mesmas problemáticas, temos desenvolvido seminários semanais de reflexão sobre o quotidiano das aulas, em particular sobre os incidentes que remetem para a ideia da diversidade cultural na sala de aula e para a necessidade de construção de novos dispositivos pedagógicos para a ação educativa; temos usado até o livro do Principezinho [o Pequeno Príncipe] para mostrar, com outra literatura eventualmente menos percebida como científica, em que consiste o contacto intercultural e a transformação do self na viagem da vida: "Aqueles que passam por nós não vão sós; não nos deixam sós. Deixam um pouco de si, levam um pouco de nós". Ou mostrando, por meio deste mesmo livro, como "O essencial é invisível aos olhos" e como a reflexividade antropológica pode ajudar a desocultar o que está por detrás de algumas evidências.

Nesta linha, a ideia é mostrar que o social e o cultural não são absolutamente exteriores ao indivíduo (Vieira, 2014); desnaturalizar e "despsicologizar" o conceito de aluno (Vieira, a. 2013 a e b), de pessoa. Efetivamente, o social e o individual passam também pelo indivíduo [não apenas o indivíduo pelos contextos], tornando-o múltiplo, construído em continuidades e descontinuidade numa socialização multicultural (Vieira; Vieira, 2007). Continua a tratar-se, efetivamente, de um trabalho antropológico, mas que 
não quer analisar as sociedades e as culturas fora do indivíduo, mas, antes, como estas permeiam os sujeitos mediados pelos educadores e outros adultos mediadores.

\section{Da mediação e da reconstrução identitária}

Posta a problemática das identidades mestiças, complexas e intermulticulturais, surge-nos agora a problemática da mediação como estratégia de comunicação entre diferentes e como mecanismo multi-hermenêutico capaz de ajudar à reconstrução identitária dos indivíduos, sujeitos com espaço para fazerem escolhas dentro dos condicionamentos socioculturais. A mediação é hoje um conceito que atravessa vários discursos em várias áreas disciplinares. Facilmente se ouve falar de mediação familiar, sociocultural, de mediação de conflitos, de mediação de seguros, mediação laboral, mediação intercultural, entre outras.

A mediação educativa, escolar e mediação sociopedagógica são, também, conceitos cada vez mais veiculados por parte dos profissionais da educação e nas intenções de alguns projetos educativos. (Caride, 2005; Peres, 2010; Vieira, 2013al

Quando nos referirmos à mediação, enquanto área e conjunto de competências transversais a várias profissões, como uma filosofia hermenêutica (Vieira; Vieira, 2007), assumimos a comunicação interpessoal e intercultural (Aguado e Herraz, 2006; Arends, 1995; Vieira, 2011; Vieira, 2013 a e b) como tradução sistemática de interesses das partes numa interação e por vontade dos implicados (Santos, 1997). Na mediação entre diferentes valores culturais, o trabalhador social e 0 educador emergem como mediadores entre os grupos sociais e as mais diversas instituições públicas e privadas, apoiando-se numa hermenêutica multitópica com vista à concretização dos direitos e dos interesses dos grupos e sujeitos em causa na interação. A finalidade do processo de mediação é buscar a autonomia desses grupos e pessoas, o tão referido, hoje, empowerment. (Vieira, 2012)

Ao trabalhar com as diversidades, isto é, com outras identidades, e ao procurar formas de ajuda à emancipação, a mediação tem vindo a desenvolverse e a especializar-se, em vários domínios, desde as Ciências Jurídicas, à Gestão, Psicologia, Antropologia, Sociologia e a temas transversais aplicados à educação.

Por vezes há uma visão simplista da mediação aplicada no nível comunitário, penal, familiar, laboral, escolar, internacional. Tal pode levar-nos a considerar como uma via secundária de condução de conflitos, em que a principal é a via legal. Se for feita uma reflexão mais pormenorizada, descobrem-se os 
inumeráveis valores compreendidos no processo de mediação (Bonafé-Schmit, 1992). Para Six (1990, p. 11), “a mediação sempre existiu. Sempre houve, nas tribos ou povoações, sábios a quem se recorria com toda a naturalidade, que traziam sossego às pessoas diferentes, seres que eram alicerces da fraternidade". A figura do mediador está, assim, ligada a uma pessoa razoável e amante da Justiça, com capacidade para dialogar e utilizadora de um senso comum relacional, que the dá capacidade para participar em conflitos alheios sobre os quais exerce uma ação reestruturante.

As Ciências da Educação têm também procurado analisar o papel da escola na sociedade, evidenciando a forma como a segunda determina ou condiciona a primeira. Neste contexto, emergem as discussões sobre a necessidade do mediador e sua profissionalização no sistema de educação e de formação, uma vez que a dinâmica social se joga nas intermediações dos processos de reprodução e de transformação das relações sociais de que é feita a vida escolar (Almeida, 2010). Para Helena Almeida, por seu lado,

A mediação potencia a construção de laços sociais, e constitui, inclusive, uma nova abordagem no processo de inclusão social, quando operacionalizada no domínio social e cultural. Por exemplo, os profissionais que trabalham com grupos de ciganos, luso-africanos e africanos imigrados em Portugal, deparam-se com pessoas marcadas pelas múltiplas diferenças culturais com a sociedade de acolhimento, tais como diferenças de identidade étnica, de cultura, de padrões de comportamento e organização social [...]. (Almeida, 2009, p. 118)

Essas diferenças tendem a ser reconfiguradas como desigualdades, tendem a induzir ou até a justificar assimetrias, privações e marginalizações a que os membros daqueles grupos são sujeitos, o que dificulta ou mesmo impede a realização dos seus direitos pessoais, o desenvolvimento de sentimentos de autoestima e respeito, a sua inserção familiar, social, laboral, profissional, cívica e a sua relação com as instituições, as normas e as rotinas da sociedade englobante.

Também o professor é, por excelência, um mediador; no mínimo um facilitador, intermediário e incentivador entre o aluno e o conhecimento. Neste sentido, pode aproximar as duas partes, aluno e conhecimento, servindo como elo deste encontro. Uma boa relação pedagógica assenta, necessariamente, numa boa relação de mediação entre aluno, professor e conhecimento. Mas o professor pode ser, também, um mediador de tensões e conflitos que surgem na sala de aula e na escola em geral.

Paulo Freire insistiu na ideia de que não é possível ensinar sem aprender e 
sem escutar. Na "Pedagogia da Autonomia", falando dos saberes fundamentais à prática educativo-crítica, Paulo Freire refere que

não há docência sem discência, as duas se explicam e seus sujeitos, apesar das diferenças que os conotam, não se reduzem à condição de objeto, um do outro. Quem ensina aprende ao ensinar e quem aprende ensina ao aprender. (Freire, 2006, p. 42)

Para Rosa Marí Ytarte, uma investigadora da área da mediação intercultural, a mediação socioeducativa é

a ação educativa cujo ponto de partida é estar disponível para discutir a relação entre as identidades, dar voz e ouvir as razões a esses "outros" a quem chamamos de diferentes. Entenda-se que, para que uma ação seja mediadora de comunicação, ela terá que se basear na premissa de que todos os participantes devem sentir-se igualmente bem-vindos e reconhecidos pelo que são. (Marí Ytarte, 2010, p. 101)

A mediação com a família e a comunidade terá, também, de ser no sentido de ensinar a aprender a conviver, quer dizer, a viver com (Jares, 2007) a diversidade na unidade do projeto educativo, comungado e construído por todos. Desta forma, a mediação sociopedagógica, por parte do professor, transforma-se numa mediação socioeducativa, familiar e comunitária, sendo, também, além de preventiva, de resolução de conflitos, em que alguns encarregados de educação e outros agentes sociais podem ser, também, mediadores de conflitos em conjunto com o docente.

O acompanhamento dos alunos é, hoje, cada vez mais, assumido como a pedra basilar do sucesso educativo. A intervenção formativa, dirigida a alunos de grupos sociais diversos, poderá traduzir-se em mediação entre o aluno, a ação educativa e o exterior; com a família, comunidade, serviços sociais, de saúde, etc., numa abordagem integrada e centrada no aluno.

Esse acompanhamento concretiza-se de um modo particularmente significativo no âmbito da mediação sociocultural. A escola, que se quer para todos, tem a obrigação, enquanto instituição, ela própria mediadora, de favorecer o acesso e o sucesso escolar de todos os alunos, encontrando processos de comunicação intercultural e de inclusão.

O ideário da "escola para todos" tornou a escola mais permeável e desperta para os problemas sociais e a multiculturalidade nas escolas. 0 processo educativo tornou-se, assim, uma questão ainda mais social e cultural e não meramente pedagógica. Nesta linha, o professor deverá ser o mediador de aprendizagens e da comunicação entre identidades e alteridades, promovendo 
os valores da convivência e da hospitalidade, e assumindo algumas mestiçagens culturais como processos/produtos fundamentais à vida conjunta sem se abolirem as particularidades que os grupos e pessoas pretendem preservar.

\section{Em jeito de conclusão}

Pensamos ter ficado claro o uso compreensivo de narrativas biográficas e de histórias de vida como um caminho metodológico, de cariz etnográfico, fundamental para compreender como a realidade social exterior se incorporou no self que se torna pluricultural/mestiço com inúmeras possibilidades de gestão das suas pertenças. Nesta via investigativa, o investigador preocupase em compreender detalhadamente e aprofundadamente o que é que os sujeitos pensam, como é que desenvolvem os seus quadros de referência e como é que se apresentam no quotidiano e gerem as suas várias identidades pessoais ou pertenças identitárias, assumindo, ou não, a mestiçagem de si.

Considerando a metáfora produzida por Michel Serres (1993), embora nasçamos numa margem do rio, esse lugar inicial do eu pessoal e social não corresponderá a todos os lugares que o sujeito habitará no seu percurso de vida. A transformação social de cada indivíduo é ininterrupta: cada aprendizagem é transformação; é espaço de mestiçagem. Ninguém é apenas de um lugar. $E$, sendo os sujeitos do mundo contemporâneo cada vez mais socializados em contextos multiculturais, urge compreender como cada um se forma e se identifica e qual o papel dos adultos mediadores, sejam eles profissionais ou não, na (re)contrução do eu mestiço.

A escola tornada obrigatória, como é o caso de Portugal, até ao $12 .^{\circ}$ ano de escolaridade, levou a um aumento da multiculturalidade e a um repensar as pedagogias por forma a construir espaços e tempos de inclusão e a trabalhar a identidade pessoal e cultural dos alunos de uma forma mediadora, sem ser, portanto, impositiva, e deixando algum espaço para que cada aluno possa construir caminhos e identificações mestiças entre a cultura de origem e a cultura hegemónica promovida pela escola. Por isso, o processo educativo não pode ser mais visto como meramente pedagógico e didático, mas, antes, de natureza sociopedagógica em que a mediação intercultural, seja promovida por docentes, seja promovida por outros profissionais sociais a integrar a escola, tem um papel predominante para buscar o diálogo entre os particularismos e os universalismos da cultura e para prevenir e resolver tensões e conflitos sociais que são o reflexo da sociedade na escola. 


\section{Referências}

ABDALLAH-PRETCEILLE, Martine. Vers une pedagogie interculturelle. Paris: INRP, 1990.

AGUADO, Teresa e HERRAZ, Mercedes. Mediación social intercultural en el ámbito socioeducativo. Portularia, vol. VI, 1, Universidade de Huelva, 2006.

ALMEIDA, Helena Neves. Um panorama das mediações nas sociedades. Na senda da construção de sentido da mediação em contexto educativo. In: VEIGA SIMÃO, Ana. Margarida; CAETANO, Ana Paula e FREIRE, Isabel. (Orgs.) Tutoria e Mediação em Educação. Lisboa: Educa, 2009. 115-128.

ALMEIDA, Vítor. O Mediador sociocultural em contexto escolar - contributos para a compreensão da sua função social. Mangualde: Edições Pedago, 2010.

ANDRÉ, João. Diálogo intercultural, utopia e mestiçagem em tempos de globalização. Coimbra: Ariane Editora, 2005.

. Multiculturalidade, identidades e mestiçagem: o diálogo intercultural nas ideias, na política, nas artes e na religião. Coimbra: Palimage, 2012.

ANZALDÚA, Gloria. Borderlands/La Frontera: The New Mestiza. San Francisco: Aunt Lute Books, 1987.

ARENDS, Richard. Aprender a ensinar. Lisboa: Editora McGraw-Hill, 1995.

BASTIDE, Roger. Le Principe de Coupure et le Comportement Afro-Brésilien. In: Anais do XXXI Congresso Internacional de Americanistas. S. Paulo: Anhembi, Vol I, 1955. 493-503.

BONAFÉ-SCHMIT, Jean Pierre. La médiation: une justice douce. Paris: Syros, 1992.

BOURDIEU, Pierre. Esboço para uma auto-análise. Lisboa: Edições 70, 2005.

BROCKMAN, Jonh. A Terceira cultura. Lisboa: Temas e Debates, 1998.

CAMILLERI, Carmel. Les conditions structurelles de l'interculturel. In: Revue Française de Pédagogie, n 103, abr./maio/jun. 1993. pp.43-50.

CAMILLERI, Carmel; COHEN-EMERIQUE, Margali. (Dir.). Chocs des cultures; concepts et enjeux pratiques, Paris: L' Harmattan, 1989.

CAMILLERI, Carmel et al. Stratégies identitaires, Paris: PUF, 1990.

CAPUL, Maurice e LEMAY, Michel. Da educação à intervenção social, Vol. I e II. Porto: Porto Editora, 2003.

CARIDE, José Antonio. Las fronteras de la pedagogia social. Perspectivas científica e histórica. Barcelona: Editorial Gedisa, 2005.

CUNHA, Pedro D' Orey. Entre dois mundos. Vida quotidiana de famílias portuguesas na América. Lisboa: Secretariado Coordenador dos Programas de Educação Multicultural, Ministério da Educação, 1997.

DUBAR, Claude. A crise das Identidades - a interpretação de uma mutação. 
Porto, 2006.

FREIRE, Paulo. Pedagogia da Autonomia: saberes necessários à prática educativa. São Paulo: Editora Paz e Terra, 2006.

GUSMÃo, Neusa Maria. Os filhos da África em Portugal - antropologia, multiculturalidade e educação. Lisboa: Imprensa de Ciências Sociais, 2004. HALL, Stuart. The Question of Cultural Identity, D. Hall \& A. McGrew (eds.). Modernity and Its futures. Cambridge: Polity Press, 1992. 274-316.

. Da diáspora - identidades e mediações culturais. Belo Horizonte: Editora UFMG, 2003a.

A identidade cultural na pós-modernidade, Brasil: DP\&A Editora, 2003b.

HOMI K. Culture's in Between, S. Hall \& P. du Gay leds.). Cultural Identity. London: Sage, 1996. pp.53-60.

JARES, Xesus Rodrigues. Pedagogia da convivência. Porto: Profedições, 2007. LAPLANTINE, François; NOUSS, Alexis. A mestiçagem. Lisboa: Instituto Piaget, 2002.

MAALOUF, Amin. Identidades assassinas. Lisboa: Difel, 2002.

MAGALHÃES, António. 0 síndroma da Cassandra: reflexividade, a construção de identidades pessoais e a escola. In: STOER, Stephen; CORTESÃO, Luisa e CORREIA, José Alberto. (Orgs.).Transnacionalização da educação: da crise da educação à «educação» da crise, Porto: Edições Afrontamento, 2001. 301-338.

MARÍ YTARTE, Rosa. Mediación socioeducativa desde una perpectiva intercultural. In: PERES, A. N. e VIEIRA, R. (Orgs.) Educação, justiça e solidariedade na construção da paz. Chaves e Leiria: APAP e CIID-IPL, 2010. 100-115.

NóVOA, António; FINGER, Matthias. O método auto(biográficol e formação. Lisboa: Ministério da Saúde, 1988.

O'NEILL, Brian. Displaced Identities among the Malacca Portuguese, S. Parkhurst \& S. Roseman (eds.). Recasting Culture and Space in Iberian Contexts. New York: SUNY Press, 2008. pp.55-80.

PERES, Américo Nunes e VIEIRA, Ricardo. Educação, justiça e solidariedade na construção da paz. Amarante: APAP e CIID, 2010.

PERRENOUD, Phillipe. Práticas pedagógicas, profissão docente e formação, Lisboa: D. Quixote, 1993.

PINEAU, Gaston. Produire sa Vie: autoformation et autobiographie. Montreal: Ediligo, 1983.

SARUP, Madam. Identidade, cultura e o mundo pós-moderno. Edimburgo: Edinburgh University Press, 1996.

SERRES, Michel. O Terceiro Instruído. Instituto Piaget: Lisboa, 1993. 
SIX, Jean-François. Les temps des mediateurs. Paris: Seuil, 1990.

TORREMORELL, Maria Carme Bouqué. Cultura de mediação e mudança social. Porto Editora, 2008.

VELHO, Gilberto. Individualismo e cultura - notas para uma antropologia da sociedade contemporânea, Rio de Janeiro: Jorge Zahar Editor, 1987.

VIEIRA, Ana e VIEIRA, Ricardo. Diversidade cultural e mediação escolar. A Página da Educação. Disponível em.<http://www.apagina.pt/?aba=7\&cat=164 $\& d o c=12127 \& \mathrm{mid}=2>$. Acesso em: 30. Maio. 2014.

VIEIRA, Ana. Pedagogia social nas escolas: um olhar sobre a mediação e a educação social, Cadernos de Pedagogia Social, $n^{\circ}$ 4, Porto: Universidade Católica, 2012. pp.9-26.

. Educação social e mediação sociocultural. Porto: Profedições, 2013a. . Da educação e da mediação de tensões sociais, indisciplina e violência na Escola. In Caderno Pedagógico. Lajeado, v.10, n.2, 2013b. pp.183-198. VIEIRA, Ricardo. Histórias de vida e identidades, professores e interculturalidade. Porto: Edições Afrontamento, 1999a.

. Serigual ser diferente: encruzilhadas da identidade, Porto: Profedições, 1999b.

Identidades pessoais - interacções, campos de possibilidade e metamorfoses culturais. Lisboa: Colibri, 2009.

. Educação e diversidade cultural: notas de antropologia da educação.

Porto: Afrontamento e Leiria: CIID-IPL, 2011.

. Life stories, cultural métissage and personal identities. SAGE Open, Jan 2014, 4(1), DOI: 10.1177/2158244013517241. 2014. p.1-13. Disponível em:< http://sgo.sagepub.com/content/4/1/2158244013517241>. Acesso em: 30. Maio. 2014

VIEIRA, Ricardo e TRINDADE, José Maria. Migration, culture and identity, Portugal, LAIC - Language and Intercultural Communication, vol. 8, 1, 2008. pp.36-49.

VIEIRA, Ricardo, Margarido, Cristóvão \& Marques, José. Partir, chegar, voltar... reconfigurações identitárias de brasileiros em Portugal. Porto: Afrontamento, 2013.

WIEVIORKA, Michel. A diferença, Lisboa: Fenda Edições, 2002. 
Recebido em junho de 2014

Aprovado novembro de 2014

Ricardo Vieira é doutor em antropologia social pelo Instituto Universitário de Lisboa (ISCTE-IUL) e agregado em antropologia da educação. Coordenador principal (professor titular) na Escola Superior de Educação e Ciências Sociais Instituto Politécnico de Leria (ESECS-IPLeiria), Portugal. Investigador integrado do CIID-IPL-CICS.NOVA. E-mail: rvieiradipleiria.pt

Ana Vieira é doutora em educação social pela Universidade de Trás-os-Montes e Alto Douro (UTAD). Professora adjunta na Escola Superior de Educação e Ciências Sociais Instituto Politécnico de Leria (ESECS-IPLeiria), Portugal. Investigadora Integrada do CIID-IPL-CICS.NOVA. E-mail: ana.vieira@ipleiria.pt 